\title{
ENSO Teleconnections and Impacts on U.S. Summertime Temperature during a Multiyear La Niña Life Cycle
}

\author{
BOR-TING JONG \\ NOAA Physical Sciences Laboratory, Boulder, Colorado, and Department of Earth and Environmental Sciences, Columbia \\ University, New York, and Lamont-Doherty Earth Observatory, Columbia University, Palisades, New York \\ MingFAng TING AND RICHARD SEAGER \\ Lamont-Doherty Earth Observatory, Columbia University, Palisades, New York \\ WESTON B. ANDERSON \\ International Research Institute for Climate and Society, Palisades, New York
}

(Manuscript received 19 September 2019, in final form 31 March 2020)

\begin{abstract}
El Niño-Southern Oscillation (ENSO) teleconnections have been recognized as possible negative influences on crop yields in the United States during the summer growing season, especially in a developing La Niña summer. This study examines the physical processes of the ENSO summer teleconnections and remote impacts on the United States during a multiyear La Niña life cycle. Since 1950, a developing La Niña summer is either when an El Niño is transitioning to a La Niña or when a La Niña is persisting. Due to the distinct prior ENSO conditions, the oceanic and atmospheric characteristics in the tropics are dissimilar in these two different La Niña summers, leading to different teleconnection patterns. During the transitioning summer, the decaying El Niño and the developing La Niña induce suppressed deep convection over both the subtropical western Pacific (WP) and the tropical central Pacific (CP). Both of these two suppressed convection regions induce Rossby wave propagation extending toward North America, resulting in a statistically significant anomalous anticyclone over northeastern North America and, therefore, a robust warming signal over the Midwest. In contrast, during the persisting summer, only one suppressed convection region is present over the tropical CP induced by the La Niña SST forcing, resulting in a weak and insignificant extratropical teleconnection. Experiments from a stationary wave model confirm that the suppressed convection over the subtropical WP during the transitioning summer not only contributes substantially to the robust warming over the Midwest but also causes the teleconnections to be different from those in the persisting summer.
\end{abstract}

\section{Introduction}

El Niño-Southern Oscillation (ENSO) influences the interannual variability of North American hydroclimate not only in winter (e.g., Ropelewski and Halpert 1986, 1987; Mason and Goddard 2001; Larkin and Harrison 2005; Jong et al. 2016) but also in summer (e.g., Ropelewski and Halpert 1986; Ting and Wang 1997; Wang et al. 2007). Previous studies have suggested that ENSO can exert significant impacts on crop yields over North America during the summer growing season (e.g., Handler 1984; Iizumi et al. 2014; Anderson et al. 2017). However, the less-established understanding of ENSO summer teleconnections might

Corresponding author: Bor-Ting Jong, bor-ting.jong@noaa.gov be leading to poor forecasting skill in the Northern Hemisphere summer extratropical circulations, in sharp contrast to the demonstrated skill of boreal winter ENSO-based seasonal climate forecasts (e.g., Wang et al. 2009; Ding et al. 2011). To address the knowledge gap in ENSO summer teleconnections, this study focuses on the different physical mechanisms of summer teleconnections and characteristics of remote impacts on the United States in the summer that arise from the multiyear evolution of ENSO.

A typical ENSO event develops in late boreal spring, peaks at the end of the calendar year, and decays in the following spring to early summer (e.g., Rasmusson and Carpenter 1982; Okumura and Deser 2010). During an ENSO event, anomalous tropical deep convection 
induced by sea surface temperature (SST) anomalies triggers an upper-level Rossby wave propagating from the equator to the extratropics across the Pacific-North America (PNA) region (e.g., Hoskins and Karoly 1981; Webster 1981). The low-frequency Rossby wave shifts the subtropical jet stream and storm track equatorward (poleward) during an El Niño (La Niña), subsequently influencing climate in remote regions including North America (e.g., Trenberth et al. 1998). Besides the direct tropical influence via Rossby wave propagation, midlatitude transient eddies also play an important role in maintaining and modulating the extratropical response to the ENSO tropical forcing through an eddy-mean flow positive feedback (e.g., Hoerling and Ting 1994; Harnik et al. 2010; Seager et al. 2010). Both mechanisms are tightly linked to the intensity and location of the subtropical jet stream (e.g., Hoskins and Ambrizzi 1993; Hoerling and Ting 1994). Thus, the teleconnections and their impacts on extratropical North America are the strongest in the boreal winter when the ENSO tropical forcing reaches its peak and the jet stream is strong and closest to the tropics, allowing the Rossby wave source originating from tropical diabatic heating anomalies to extend into westerly flows and, hence, allowing Rossby wave propagation into midlatitudes (e.g., Webster 1982).

These typical features of boreal winter climate, including both the ENSO tropical forcing and the mean locations of jet stream and storm track, differ in the summer season. The intensity of teleconnections is much weaker as the anomalous tropical SST and deep convection are in either the developing or decaying phases of ENSO. Further, the dominance of tropical easterlies and the weaker and poleward-shifted North Pacific jet stream limit the potential for Rossby wave propagation out of the tropics into the extratropical region (Hoskins and Karoly 1981; Webster and Holton 1982). The difficulties in establishing the regional impacts of ENSO summer teleconnections are also aggravated by stronger land-atmosphere interactions in the summer season, which, over North America, can be comparable to the impact of remote SST forcing (e.g., Koster et al. 2000; Douville 2010). These factors constrain our knowledge of ENSO teleconnections and potentially limit the model forecasting skill of seasonal regional impacts on North America.

Despite the limitations, the previous literature has demonstrated the possibility that ENSO tropical forcing can trigger Rossby waves propagating toward higher latitudes in the summer season (e.g., Lau and Peng 1992; Ding et al. 2011; Douville et al. 2011) and impact U.S. summer climate such as variability in Great Plains rainfall (Ting and Wang 1997; Hu and Feng 2001) and the Great Plains low-level jet (Weaver and Nigam 2008; Liang et al.
2015). In particular, a continental-scale anomalous anticyclone typically sits over North America in the summer of a developing La Niña and thereby leads to hot and dry summers over the central United States (Wang et al. 2007). The strong rise in maximum temperature and decrease in precipitation over major crop-producing area of the United States in the developing La Niña summer were found to negatively affect maize and soybean yields (Anderson et al. 2017). This negative impact on agricultural production and the associated economic losses and social impact highlight the importance of better understanding the physical mechanisms that control the extratropical teleconnections in the developing La Niña summers. In establishing the physical processes of ENSO summer teleconnections, however, the multiyear evolution of ENSO was rarely considered in the previous literature.

The importance of the multiyear ENSO evolution originates from the nonlinearity and asymmetry in the evolution and duration of El Niño and La Niña events. A La Niña tends to persist through the following summer and often reintensifies in the subsequent winter, leading to a multiyear La Niña event (McPhaden and Zhang 2009; Okumura and Deser 2010; Dommenget et al. 2013). Unlike La Niña, an El Niño tends to decay rapidly in the tropical Pacific in the boreal spring, but El Niñoinduced warming in the Indian Ocean can persist into the following summer and impact the global circulation, especially in the PNA region (e.g., Lau et al. 2005; Xie et al. 2009). There have been various atmospheric and oceanic mechanisms proposed to explain the asymmetric duration of ENSO events (e.g., Okumura 2019). In the ocean, the equatorial heat content discharge during strong El Niño may favor the subsequent development of multiyear La Niñas (DiNezio and Deser 2014; DiNezio et al. 2017; Wu et al. 2019). In the atmosphere, the nonlinear response of deep convection to SSTs results in an eastward-shifted and stronger center of deep convection anomalies during an El Niño compared to a La Niña, leading to a correspondingly eastward-shifted zonal wind response (e.g., Okumura and Deser 2010; Dommenget et al. 2013). This makes easterlies over the western Pacific induced by the Indian Ocean warming during an El Niño more effective at terminating the event than their counterparts are during La Niña (Okumura and Deser 2010; Okumura 2019). On the other hand, stronger surface wind anomalies during El Niño result in stronger negative oceanic feedback, accelerating the termination of an $\mathrm{El}$ Niño relative to a $\mathrm{La}$ Niña (Dommenget et al. 2013). Nevertheless, the origin of the asymmetric evolution of ENSO events is still an active research question and nonlinearities in ocean thermodynamics might also contribute (e.g., Okumura 
2019; Wu et al. 2019). Our focus here is on the impact of the asymmetry on teleconnections.

In fact, all the first-year La Niñas since 1950 transitioned from El Niño winters (https://origin.cpc.ncep.noaa.gov/ products/analysis_monitoring/ensostuff/ONI_v5.php).

Therefore, La Niña summers can be when an El Niño is transitioning to a La Niña or when a La Niña is persisting from one year to the next. These two different cases were both loosely defined as "developing La Niña" in most of the previous studies despite the distinct prior ENSO conditions. The difference in the prior El Niño or La Niña conditions may also lead to distinct teleconnections in these two different La Niña summers, one transitioning from El Niño and one persisting from La Niña. For example, the aforementioned drops in the U.S. maize and soybean yields are uniquely observed in the developing summer of a first-year La Niña. That is, when an El Niño is transitioning to a La Niña, but not in the developing summer of second- or third-year La Niñas, when a La Niña is persisting (Anderson et al. 2017). The different agricultural impacts imply that these summer teleconnections may involve different dynamics, which has not been explored in any prior work.

In this study, we focus on distinguishing the features of teleconnections between the two different La Niña summers (transitioning vs persisting) based on observations. The goal is to understand the physical processes that lead to the strong anomalous anticyclone that is unique in the summer when an El Niño is transitioning to a La Niña. A stationary wave model (SWM) is used to characterize the relationships between ENSO tropical forcings and teleconnections in the two types of La Niña summers. In section 2, we detail the observational data and the stationary wave model used. In section 3, we compare the evolutions of the two types of $\mathrm{La}$ Niña cases from the preceding winters to the developing $\mathrm{La}$ Niña summers based on the observations. We also identify the sources that lead to the different teleconnections in the two developing La Niña summers. In section 4, we use the SWM as a diagnostic tool to test the hypothesis derived from the observational analyses. Conclusions and a discussion are provided in section 5 .

\section{Data and method}

\section{a. Observed data}

SST data are taken from the Extended Reconstructed Sea Surface Temperature, version 5 (ERSSTv5; Huang et al. 2017). ERSSTv5 provides monthly SST data from 1895 with $2^{\circ} \times 2^{\circ}$ spatial resolution. Atmospheric circulation (200-hPa geopotential height and wind) and global precipitation data are taken from the National Centers for Environmental Prediction-National Center for Atmospheric Research Reanalysis 1 (NCEP-NCAR R1; Kalnay et al. 1996). This dataset provides monthly values from 1948 to the present with $2.5^{\circ} \times 2.5^{\circ}$ spatial resolution for pressure-level data and T64 Gaussian grid for surface data. For monthly surface temperature over land area, we use the $0.5^{\circ} \times 0.5^{\circ}$ spaced Climate Research Unit TS3.26 (Harris et al. 2014) available from 1901 to 2016. The monthly climatology used in this study is consistently based on averages from January 1950 to December 2014. The SST and surface temperature over land area are both linearly detrended, and the trend is removed for each 3-month season separately.

\section{b. Definition of El Niño and La Niña events}

El Niño and La Niña events are selected based on the oceanic Niño index (ONI), a 3-month running mean of SST anomalies in the Niño-3.4 region $\left(5^{\circ} \mathrm{N}-5^{\circ} \mathrm{S}, 170^{\circ}-120^{\circ} \mathrm{W}\right)$ from ERSSTv5, relative to a 30-yr climatology. The 30-yr base period is updated every 5 years and centered to the first year of these 5 years [for a complete description, see the NOAA Climate Prediction Center (CPC) website: https:// origin.cpc.ncep.noaa.gov/products/analysis_monitoring/ ensostuff/ONI_change.shtml]. El Niño and La Niña events are defined when the ONI reaches the threshold of $+0.5^{\circ} \mathrm{C}$ and $-0.5^{\circ} \mathrm{C}$ for at least 5 consecutive overlapping 3-month averages.

Based on these criteria, we identified 4 single-year La Niña events from 1950 to 2014 (1964, 1988, 1995, 2005, indicated by purple lines in Fig. 1), 5 two-year La Niña events (1954-55, 1970-71, 1983-84, 2007-08, 2010-11, blue lines in Fig. 1), and 2 three-year La Niña events (1973-75, 1998-2000, orange lines in Fig. 1). Therefore, there are 11 first-year La Niña winters (indicated by the black dots in Fig. 1). The preceding winters of these first-year La Niña were all identified as El Niño winters (Fig. 1). We categorize the summers in the firstyear La Niña developing phase as "transitioning summer" [denoted as $\operatorname{JJA}(0)_{T}$ in all the figures]. On the other hand, there are 7 second-year La Niña winters (triangles in Fig. 1) and 2 third-year La Niña winters (diamonds in Fig. 1). We categorize the summers prior to these La Niña winters as "persisting summer" [denoted as $\left.\mathrm{JJA}(0)_{P}\right]$.

\section{c. Stationary wave model}

The time-dependent baroclinic model used in this study is based on the three-dimensional nonlinear primitive equations in sigma $(\sigma)$ coordinates. The model computes deviations from a prescribed zonally varying climatological mean state in response to imposed zonally asymmetric forcings. To find a steady-state solution, we damp out the transient eddies with a 15-day interior Rayleigh drag and a 15-day Newtonian relaxation along with a scale-selective biharmonic diffusion with the coefficient of $1 \times 10^{17}$. The model includes 24 vertical 


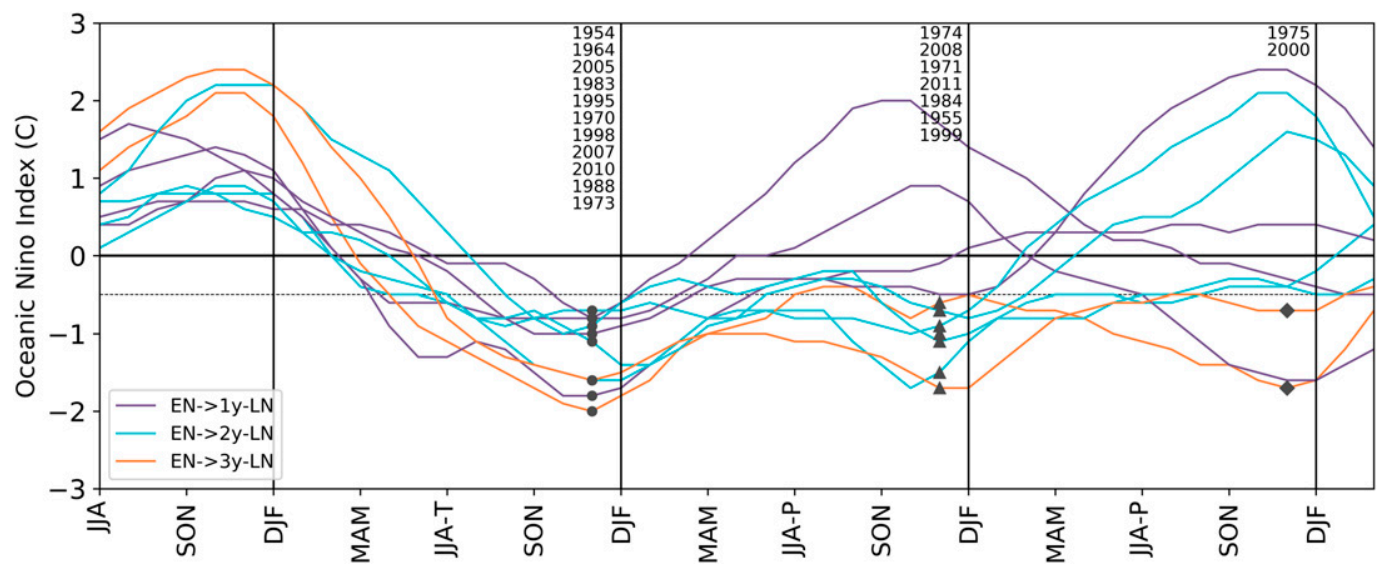

FIG. 1. Evolutions of the oceanic Niño index for the first-year La Niña during 1950-2014 from the previous year to the following two years. Purple, blue, and orange lines are for the evolutions of single-year, two-year, and three-year La Niñas, respectively. Circles, triangles, and diamonds indicate the first-year, second-year, and third-year La Niña winters (NovemberJanuary), respectively. The dotted line indicates the $-0.5^{\circ} \mathrm{C}$ threshold used to define La Niña events. The years of La Niña winters are listed in the figure.

$\sigma$ levels and a rhomboidal truncation at wavenumber 30 in the horizontal $\left(\mathrm{R} 30\right.$, roughly $2.25^{\circ}$ latitude $\times 3.75^{\circ}$ longitude). We run the model for 80 days, and the average from days 30 to 80 is shown. The SWM has been widely used as a diagnostic tool to examine the mechanisms of ENSO stationary waves in both boreal winter (e.g., Ting and Hoerling 1993; Hoerling and Ting 1994) and summer (e.g., Liu et al. 1998). More details are described in Ting and Yu (1998) and Simpson et al. (2015).

The basic state is the observed three-dimensional JuneAugust (JJA) 3-month averaged climatology (1950-2014), including temperature, horizontal wind, and surface pressure fields, obtained from the NCEP-NCAR R1. The diabatic forcings are derived from the composites of anomalous diabatic heating for transitioning La Niña summer $\left[\mathrm{JJA}(0)_{T}\right]$ and persisting La Niña summer [JJA $\left.(0)_{P}\right]$. Diabatic heating is calculated as a residual from the three-dimensional thermodynamic equation, constructed by monthly temperature and wind fields from NCEP-NCAR R1 and the transient eddy sensible heat flux convergences. As the SWM does not explicitly simulate transient eddies, the effects of midlatitude transient eddies are included by adding them as an additional forcing term. Both the transient heat and vorticity flux convergences are computed from the NCEP-NCAR R1 daily temperature and wind fields.

\section{Results}

\section{a. Observations}

\section{1) Evolution of SST ANOMALIES}

The fundamental difference between the transitioning and persisting La Niña summers originates from the evolutions of oceanic conditions. Figure 2 illustrates the evolutions of the SST anomalies from the preceding winters to the developing La Niña summers. For the transitioning La Niña, SST anomalies over the tropical Pacific evolve from an El Niño state (Fig. 2a) to a La Niña state (Fig. 2c). During the preceding El Niño winter, warm SST anomalies extend from the tropical central Pacific (CP) to the eastern Pacific (EP) and these decay rapidly in the following spring (Niño-3.4 SST anomalies drops from $1.45^{\circ}$ to $0.62^{\circ} \mathrm{C}$, Fig. $2 b$ ). By the transitioning summer $\mathrm{JJA}(0)_{T}$ (Fig. 2c), the tropical Pacific has turned into a La Niña state with negative SST anomalies from the tropical CP to EP.

Contrary to the rapidly evolving tropical $\mathrm{CP}$ and EP, the warm SST anomalies over the Indo-western Pacific and the tropical Atlantic, caused by the El Niño tropical Pacific SST anomalies via the atmospheric bridge (e.g., Alexander et al. 2002), persist from the preceding winter to the transitioning summer. The warming over the Indo-western Pacific in the boreal spring to summer is a classic delayed response to a decaying El Niño (e.g., Lau et al. 2005; Xie et al. 2009). In other words, the tropical Indian and Pacific Oceans during the transitioning summer possess the anomalies from both the decaying El Niño and the developing La Niña.

On the other hand, the oceanic conditions during a persistent La Niña evolve differently (Figs. 2d-f). In the first-year La Niña winter, cold SST anomalies extend from the tropical CP to EP, as well as the Indian Ocean and the tropical Atlantic (Fig. 2d). Following the peak season, unlike El Niño events, the tropical Pacific SST anomalies decay slowly, with Niño-3.4 SST anomalies changing from $-1.24^{\circ} \mathrm{C}$ in the winter to $-0.81^{\circ} \mathrm{C}$ in the 


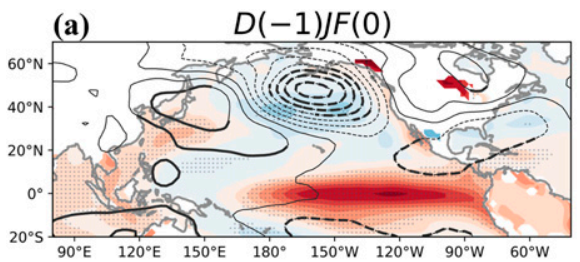

(b)

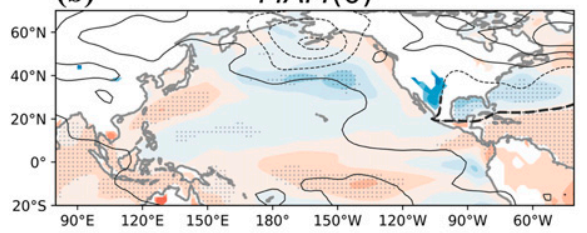

(c)

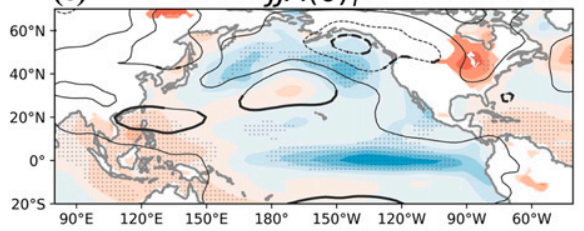

(d)

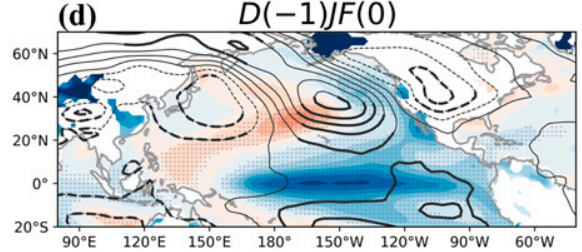

(e) $M A M(0)$

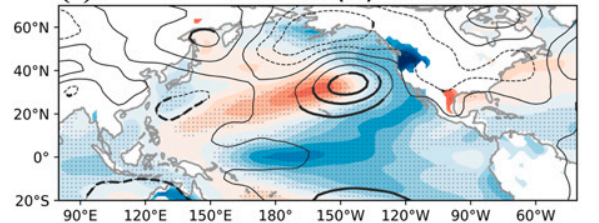

(f)

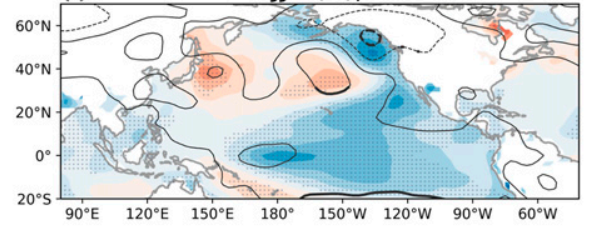

$\mu A(0)_{P}$

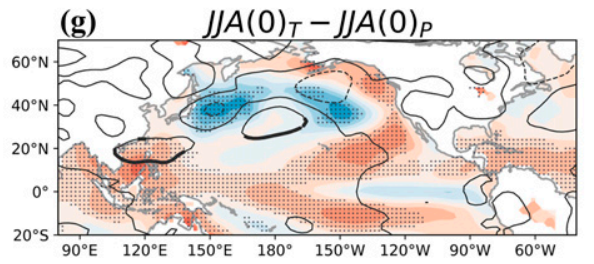

1.6

1.2

0.8

0.4

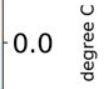
$-0.4$ $-0.8$ $-1.2$

FIG. 2. Composites of detrended ERSSTv5 SST anomalies (shaded over the ocean; ${ }^{\circ} \mathrm{C}$ ), NCEP-NCAR R1 detrended surface temperature (shaded over the land; ${ }^{\circ} \mathrm{C}$ ) and 850 -hPa geopotential height anomalies with the zonalmean removed (contours; interval: $5 \mathrm{~m}$ ) for the (left) transitioning and (right) persisting La Niña summers from (a),(d) the preceding winters December-February $[\mathrm{D}(-1) \mathrm{JF}(0)]$ and (b),(e) the preceding springs March-May $[\operatorname{MAM}(0)]$ to $(\mathrm{c}),(\mathrm{f})$ the developing La Niña summers JJA(0). The differences in the composites between the transitioning and persisting La Niña summers are shown in $(\mathrm{g})$. Stippling denotes the $90 \%$ confidence for detrended SST anomalies using a two-tailed Student's $t$ test. Thick lines indicate the $90 \%$ confidence for 850 -hPa height variations. For surface temperature over the land area, only statistically significant values (at $90 \%$ level) are present.

spring, showing the asymmetry in the duration between El Niño and La Niña evolutions (Fig. 2e). In the persisting summer $\mathrm{JJA}(0)_{P}$ (Fig. 2f), the negative SST anomalies over the tropical Pacific remain with slightly weaker intensity compared to the preceding winter and spring. Compared to the transitioning summer (Figs. 2c,g), the spatial distribution of the tropical Pacific SST anomalies is more meridionally extended. Also, the entire tropics are colder than normal, distinct from the transitioning summer in which the developing La Niña in the tropical Pacific was surrounded by warm anomalies in the Indian Ocean and tropical Atlantic persisting from the decaying El Niño.

\section{2) TropicAl RAINFALl ANOMALIES}

The distinct oceanic characteristics of each type of $\mathrm{La}$ Niña lead to different atmospheric responses over the tropical Pacific. For transitioning La Niña events, over the tropical $\mathrm{CP}$, enhanced rainfall triggered by the $\mathrm{El}$
Niño warm SST anomalies (Fig. 3a) evolves into weak reduced rainfall anomalies triggered by the developing La Niña SST anomalies (Fig. 3c). During the transitioning summer, besides the suppressed deep convection over the $\mathrm{CP}$, another significant region of suppressed deep convection appears in the subtropical western Pacific (WP; Fig. 3c). The suppressed deep convection in the subtropical WP is likely caused by the baroclinic Kelvin wave forced by enhanced precipitation over the warm Indian Ocean (Fig. 2c), which triggers low-level divergence and upper-level convergence in the subtropical WP (Xie et al. 2009). Therefore, during the transitioning summer, there is suppressed deep convection over the CP due to the developing La Niña and over the WP due to the decaying El Niño.

The warming in the Indian Ocean and the suppressed rainfall over the subtropical WP, on the other hand, are absent in the persisting summer preceded by a La Niña winter (Figs. 2f,g, 3f,g). Instead, only the suppressed 

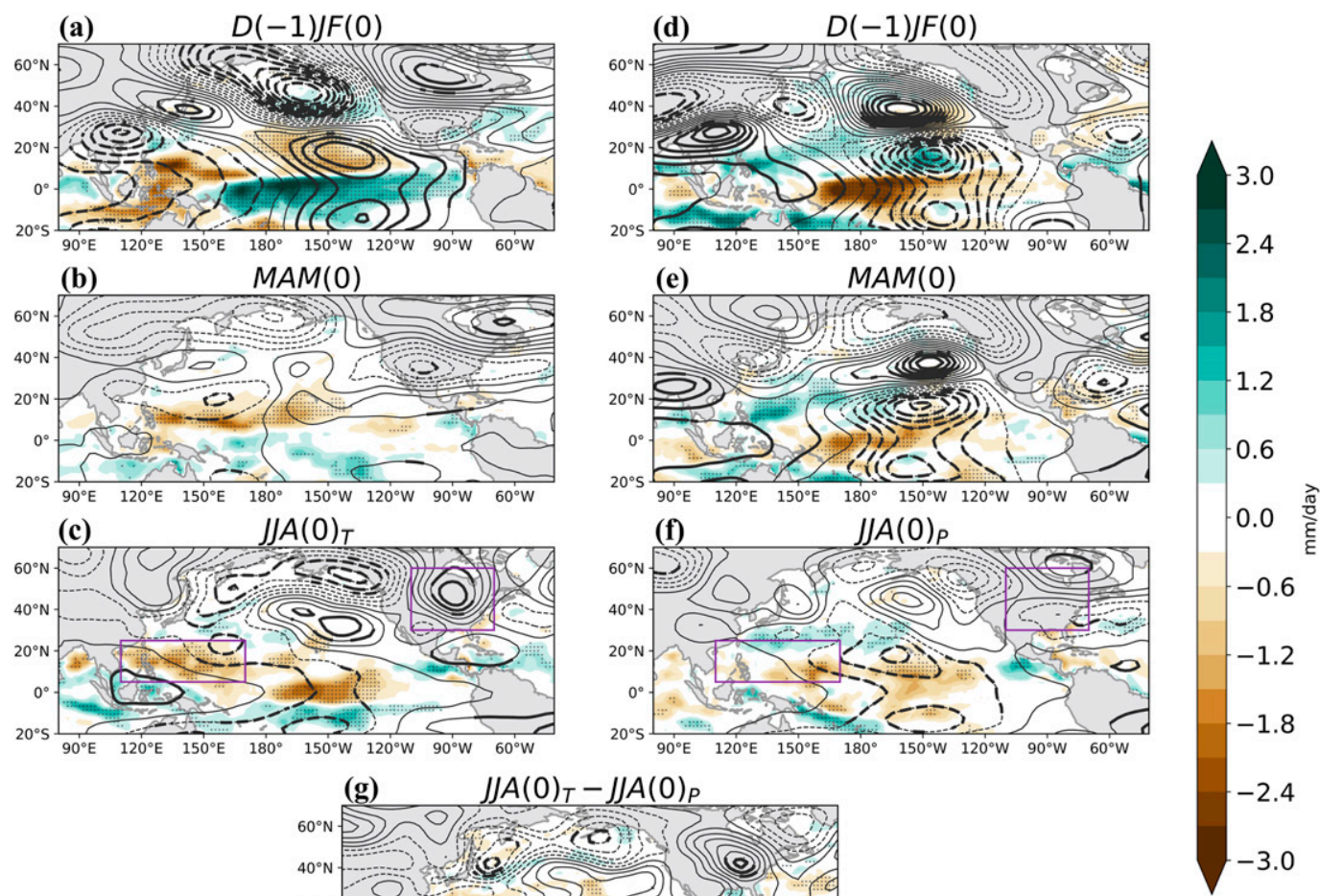

(f)

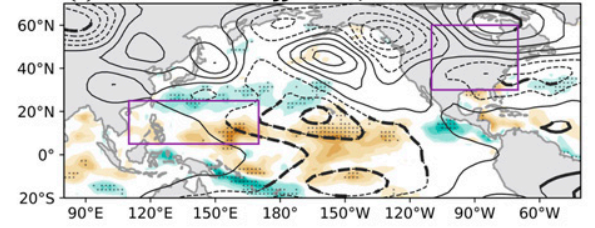

$J J A(0)_{P}$

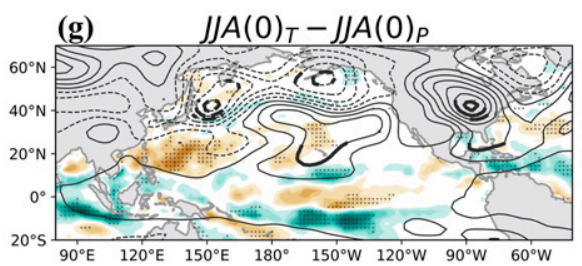

FIG. 3. Composites of precipitation anomalies (shaded; $\mathrm{mm} \mathrm{day}^{-1}$ ) and 200-hPa geopotential height anomalies with the zonal-mean removed (contours; interval: $5 \mathrm{~m}$ ) for the (left) transitioning and (right) persisting La Niña summers from (a),(d) the preceding winters $\mathrm{D}(-1) \mathrm{JF}(0)$ and (b),(e) the preceding springs MAM(0) to (c),(f) the developing La Niña summers JJA(0). The differences in the composites between the transitioning and persisting La Niña summers are shown in (g). Stippling denotes the $90 \%$ confidence for precipitation anomalies using a twotailed Student's $t$ test. Thick lines indicate the 90\% confidence for 200-hPa height variations. Purple boxes in (c) and (f) indicate the subtropical WP and eastern North America regions used in Fig. 5.

deep convection induced by the negative La Niña SST anomalies is present over the tropical CP (Fig. 3f). Accordingly, the primary difference in the anomalous rainfall field is the suppressed rainfall over the subtropical WP caused by the preceding El Niño, a unique feature to the transitioning La Niña summer. This feature is robust across multiple reanalysis datasets, including European Centre for Medium-Range Weather Forecasts interim reanalysis dataset (ERA-Interim) from 1979 to 2014 (Dee et al. 2011), Japanese 55-year Reanalysis (JRA-55) from 1958 to 2014 (Kobayashi et al. 2015), and NOAA Twentieth Century Reanalysis, version 2c (20CRv2c), from 1950 to 2014 (Compo et al. 2011) (not shown).

\section{3) Anomalous 200-hPa ATMOsPheric CIRCULATIONS}

Since ENSO teleconnections are forced by anomalous tropical convection, the distinct tropical rainfall patterns between the transitioning and persisting La Niña summers will lead to different teleconnection patterns. In the transitioning summer, significant anomalous atmospheric circulations extend from the tropics to the extratropics, with a significant anomalous anticyclone over northeastern North America (Fig. 3c). The anomalous circulation pattern over the PNA region appears to be composed of two Rossby wave trains: one from the suppressed convection over the tropical $\mathrm{CP}$ following an approximately great circle route (Hoskins and Karoly 1981), with an anticyclone in the central North Pacific, a deepened Aleutian low, and the anticyclone over northeastern North America; and another originating from the suppressed convection over the subtropical WP and propagating across the PNA region. This second wave train is composed of an anomalous low near the suppressed convection, a high anomaly in the midlatitude North Pacific (centered at around $40^{\circ} \mathrm{N}$ and $165^{\circ} \mathrm{W}$ and separate from the main high center caused by the CP cooling), a deepened Aleutian low, and the 

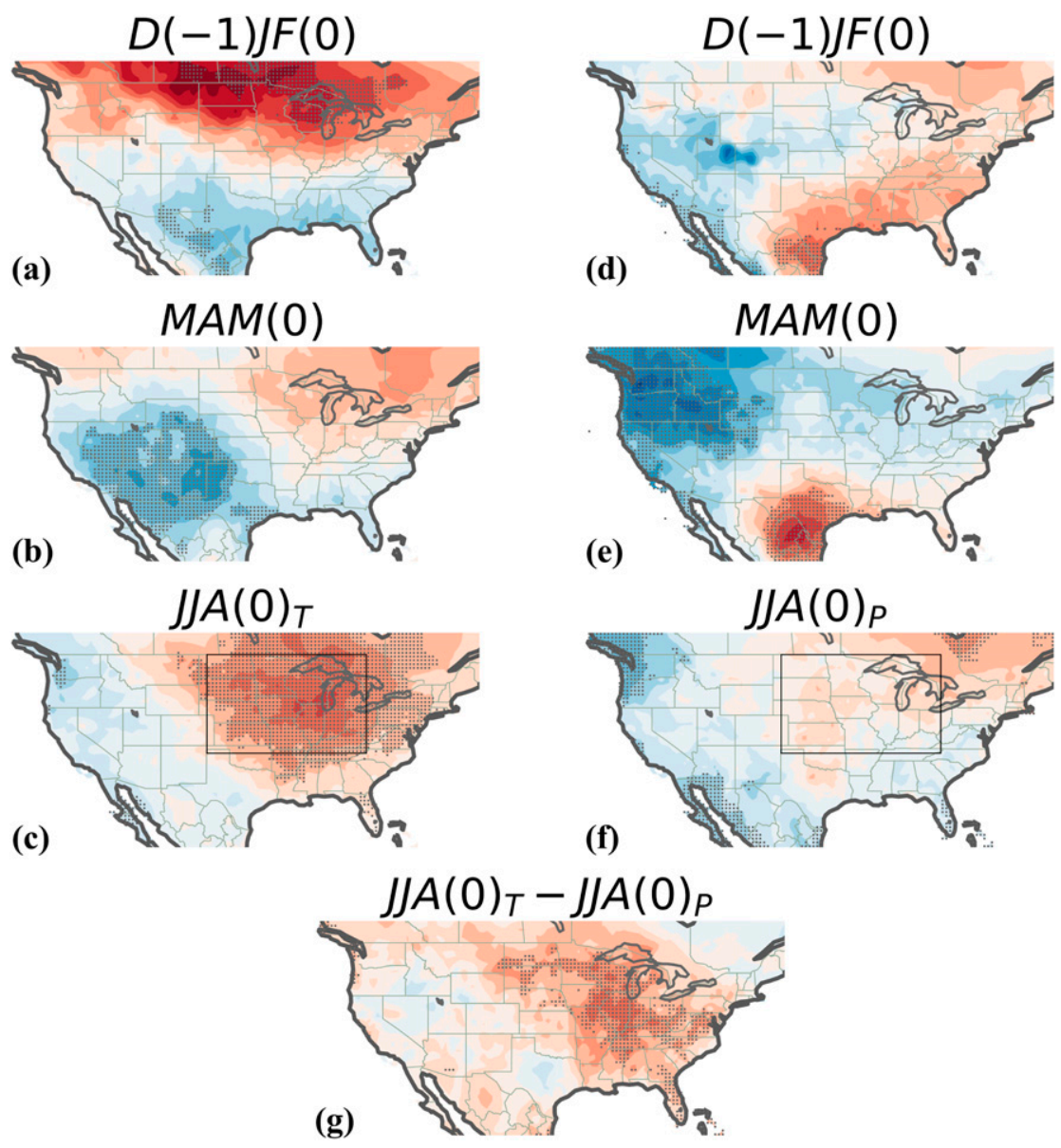

FIG. 4. As in Fig. 2, but for composites of CRU detrended surface temperature. Stippling denotes the $90 \%$ significance for detrended surface temperature anomalies using a two-tailed Student's $t$ test. Boxes in (c) and (f) indicate the Midwest area used in Fig. 5.

anomalous anticyclone over North America. It appears the two wave trains superimpose on each other and constructively contribute to the anomalous anticyclone over North America. The extratropical teleconnections are essentially barotropic, extending down to the lower level and affecting the surface climate over the United States (Fig. 2c), as will be discussed in the next subsection.

For the persisting summer, however, statistically significant anomalous atmospheric circulations are confined in the tropics, although there are indications of a single wave train emanating from the tropical CP (Fig. 3f). This teleconnection, triggered by the weak suppressed convection in the tropical CP, is weak and is not augmented by a wave train from the subtropical WP. Therefore, the teleconnection patterns over extratropical North America behave differently in these two La Niña summers: a superposition of teleconnections influences North America in the transitioning summer, but only a weak tropics-to-extratropics teleconnection exists in the persisting summer. This feature is robust across the ERA-Interim, JRA-55, and 20CRv2c datasets based on different time spans (not shown).

\section{4) U.S. SURFACE TEMPERATURE}

The atmospheric teleconnections are the bridge connecting tropical forcing and extratropical meteorological conditions. Hence, the regional impacts of ENSO on the U.S. surface climate are substantially different in these two developing La Niña summers. The evolution of the U.S. surface temperature (Ts) for the transitioning La Niña presents the classic distribution of Ts anomalies during ENSO winters, warm (cold) north-cold (warm) south dipole pattern during El Niño (La Niña) winters (e.g., Ropelewski and Halpert 1986; Figs. 4a,d). For the transitioning summer (Figs. 2c, 4c), when the teleconnections reach extratropical North America, the anomalous anticyclone, with barotropic structure, exerts significant warm anomalies on most of the area east of the Rocky Mountains, especially over the Midwest region where the anomalies are 

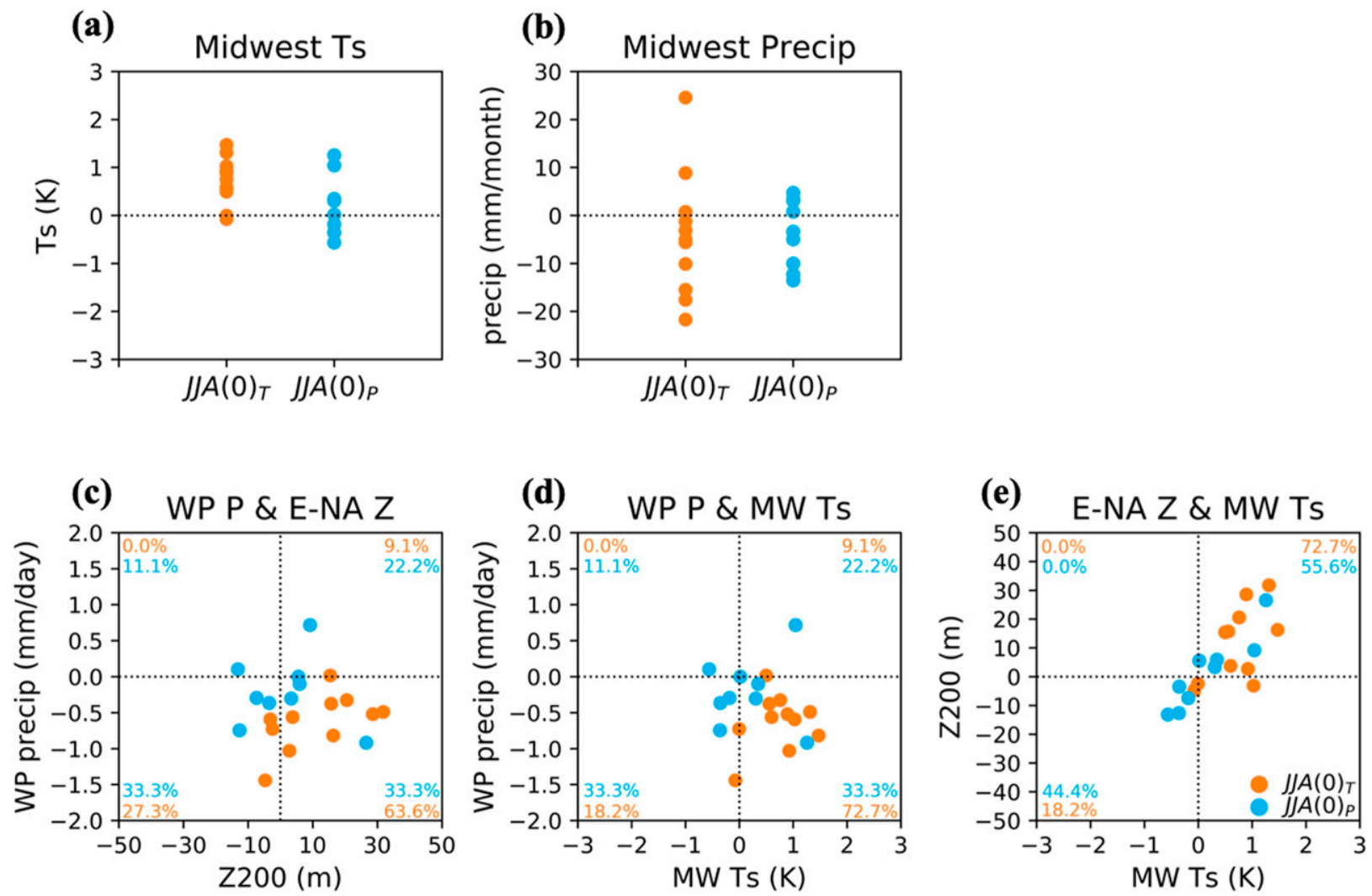

FIG. 5. Midwest CRUv3p25 detrended surface temperature (Ts) and anomalous rainfall for all (a) transitioning [JJA $(0)_{T}$, orange dots] and (b) persisting [JJA $(0)_{P}$, blue dots] La Niña summers. Scatterplots for JJA (c) subtropical WP rainfall vs 200-hPa geopotential height anomalies over eastern North America, (d) subtropical WP rainfall vs Midwest detrended Ts, and (e) 200-hPa geopotential height anomalies over eastern North America vs Midwest detrended Ts. The regions of subtropical WP and eastern North America are indicated in the Figs. 3c and 3f. The region of Midwest is presented in Figs. $4 \mathrm{c}$ and $4 \mathrm{f}$. Numbers in (c)-(e) are the percentages for JJA $(0)_{T}$ and JJA( $(0)_{P}$ in each quadrant.

more than $1^{\circ} \mathrm{C}$. The warming over the Midwest (box area in Fig. 4c) is robust, as it happened in 9 of the 11 historical transitioning summers from 1950 to 2014 (orange dots in Fig. 5a). Also, the warming has been identified in both land temperature datasets [e.g., CRU shown in Fig. $4 c$ and NCEP/Climate Prediction Center Global Historical Climatology Network (GHCN), version 2, and the Climate Anomaly Monitoring System (CAMS) datasets, not shown (Fan and van den Dool 2008)] and reanalysis datasets (e.g., NCEP-NCAR R1 shown in Fig. 2c and ERA-Interim, not shown), implying the warm anomaly is not sensitive to the particular data used. In addition, the anomalous anticyclone also leads to a dry tendency over the Midwest region: 8 of the 11 historical transitioning summers brought drier-thannormal condition to the Midwest (Fig. 5b).

For the persisting summer, the statistically significant parts of the teleconnections are mostly confined in the tropics, and the remote impacts on extratropical North America are weak and insignificant (Fig. 4f). Also, unlike in the transitioning summer, Ts anomalies over the
Midwest show no consistency among the historical persisting summers (blue dots in Fig. 5a), with half of the events showing warm anomalies and half showing cold anomalies. The strong warming over the Midwest in the transitioning summer and the much weaker response in the persisting summer reinforce the substantial differences between these two types of La Niña summers and indicate the need for better understanding the dynamics underlying the different teleconnection patterns.

\section{5) THE ROLE OF THE WP SUPPRESSED CONVECTION}

The primary difference between the two La Niña summers is the suppressed convection over the subtropical WP in the transitioning summer and its absence in the second summer. This WP suppressed convection is a robust feature during the transitioning summer: 10 out of 11 historical transitioning summers experienced drier-than-normal rainfall over the subtropical WP (Figs. 5c,d, orange dots). At the same time, positive $200 \mathrm{hPa}$ geopotential anomalies over eastern North America and the anomalously warm Midwest 

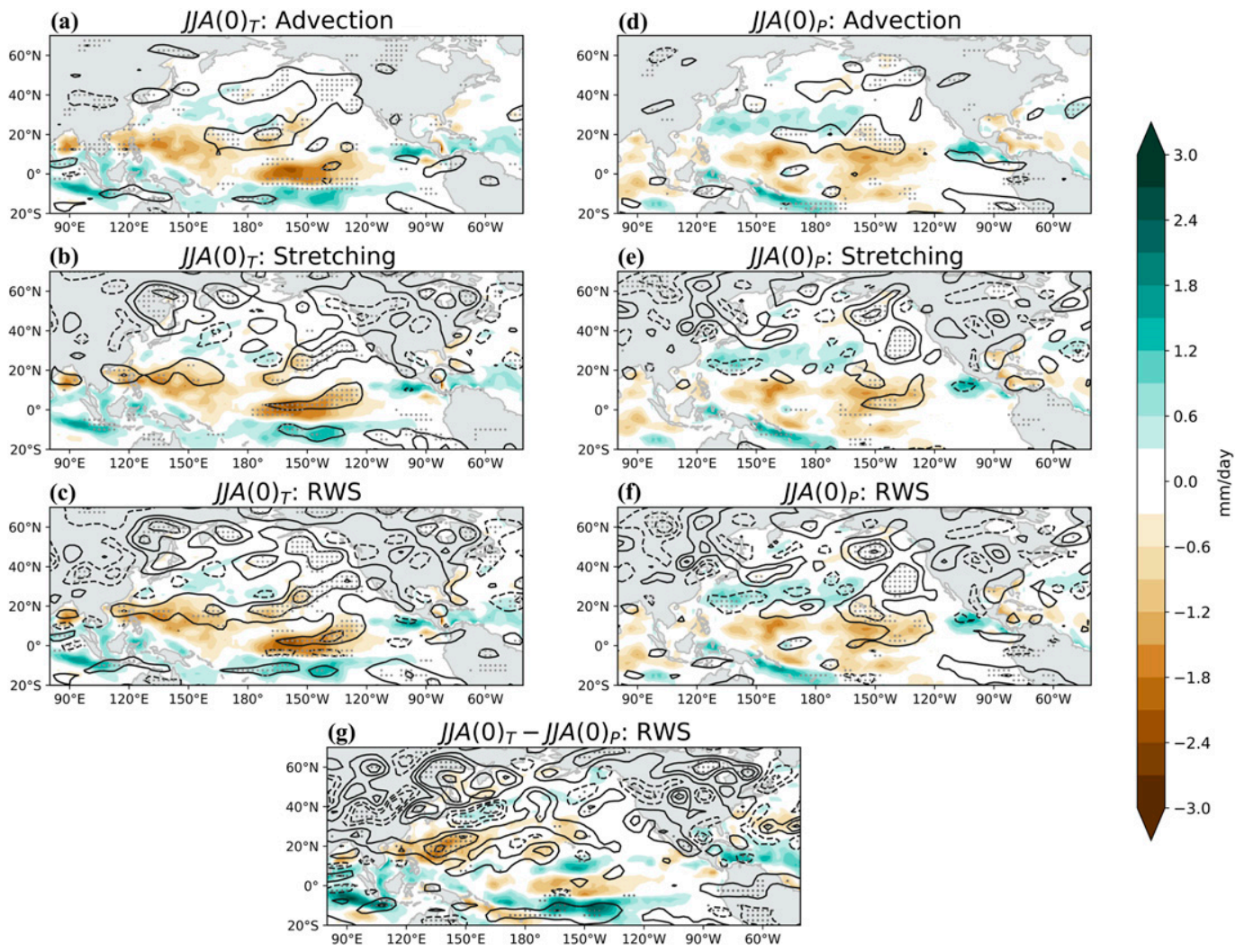

FIG. 6. Composites of precipitation anomalies (shaded; $\mathrm{mm} \mathrm{day}^{-1}$ ) and (a),(d) 200-hPa vorticity advection by anomalous divergent flow, (b),(e) stretching term due to anomalous divergence, and (c),(f) the sum of the previous two terms (contours) during the (left) transitioning and (right) persisting La Niña summers. (g) The differences in the composites of RWS between the transitioning and persisting La Niña summers, that is, (c) minus (f). The contour interval is $0.2 \times 10^{-10} \mathrm{~s}^{-2}$. The zero contour is omitted for simplicity. Stippling denotes the $90 \%$ confidence for RWS terms using a two-tailed Student's $t$ test.

Ts tend to be associated with the suppressed convection in the subtropical WP (Figs. 5c-e, orange dots). Yet these features are not as connected to the subtropical WP in the persisting summer (Figs. 5c,d, blue dots). Therefore, we hypothesize that this El Niño-induced WP suppressed convection and the associated Rossby wave strengthen the extratropical teleconnection patterns induced by the developing La Niña SST forcing, resulting in a strong anomalous anticyclone over the United States during the transitioning summer.

To test the hypothesis, we first calculate the Rossby wave source (RWS), which represents the anomalous vorticity source produced by upper-level divergence due to anomalous convective activities in the tropics (e.g., Sardeshmukh and Hoskins 1988).

The RWS is defined as

$$
\mathrm{RWS}=-\mathbf{V}_{\chi}^{\prime} \cdot \nabla(\bar{\zeta}+f)-(\bar{\zeta}+f) \nabla \cdot \mathbf{V}_{\chi}^{\prime},
$$

where ( ${ }^{-}$) and ()$^{\prime}$ represent the climatological threemonth mean and perturbation, respectively; $\mathbf{V}_{\chi}$ is the divergent component of the wind field; $\zeta$ is the relative vorticity; and $f$ is the Coriolis parameter. The first term on the right-hand side represents the vorticity advection by anomalous divergent flow, and the second term is the vorticity stretching term due to anomalous divergence.

Figure 6 presents the contribution to the RWS from the vorticity advection by the anomalous divergent flow (first term; upper panels in Fig. 6) and from the stretching term due to anomalous divergence (second term; middle panels in Fig. 6) during the transitioning and persisting La Niña summers. During the transitioning summer, significant positive vorticity forcing due to stretching is found near the regions of suppressed convection in both the subtropical WP and tropical CP (Fig. 6b). This is expected from the local response to tropical thermal forcing: anomalous suppressed convection triggers anomalous convergence in the upper levels and subsequently a Rossby wave propagation farther downstream. In particular, the suppressed convection over the subtropical WP during the transitioning summer provides an anomalous vorticity source that induces Rossby wave propagation toward extratropical North America. On the other hand, during the persisting summer, the RWS due to anomalous upper-level 

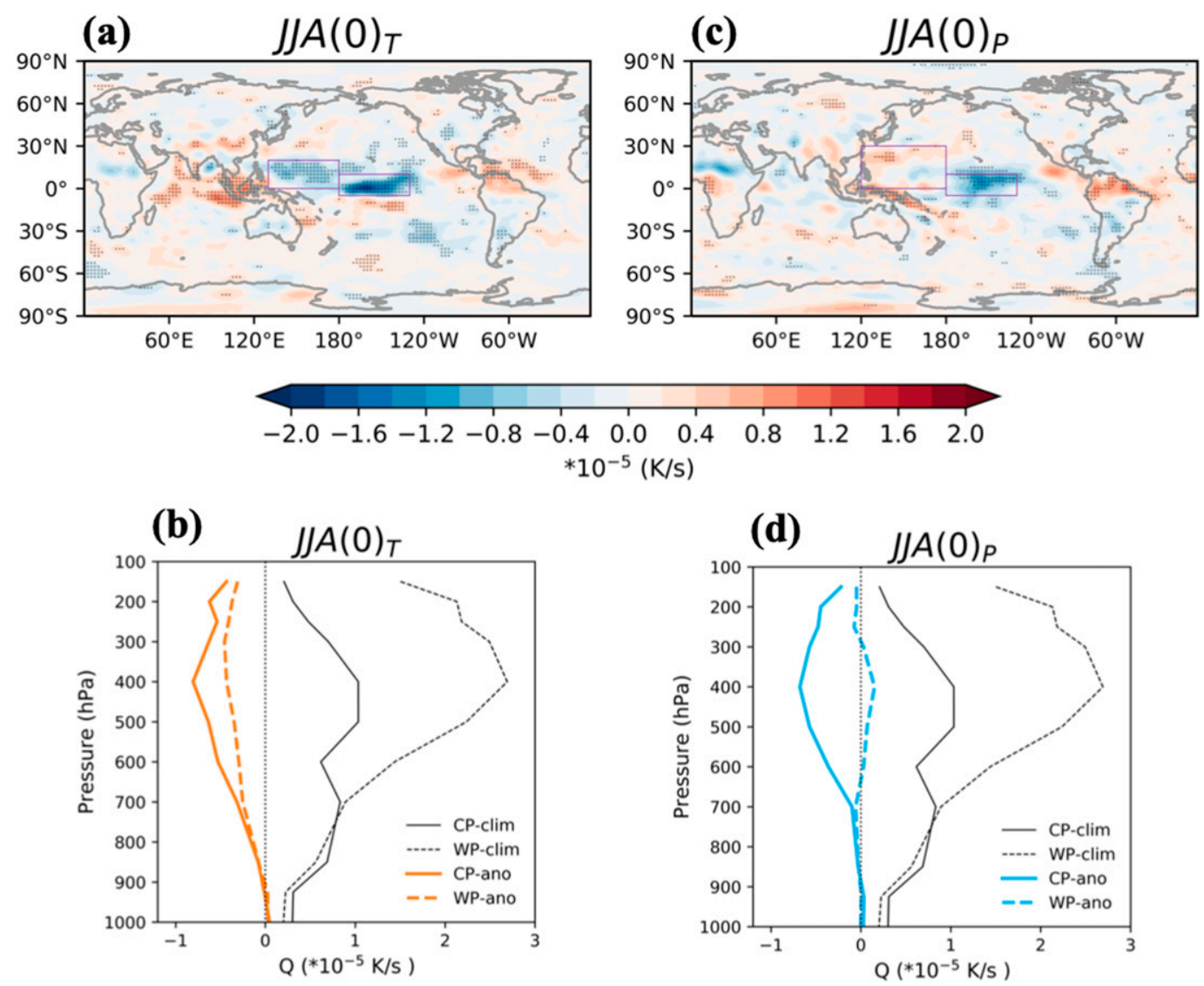

FIG. 7. Composites of anomalous diabatic heating during the (a),(b) transitioning and (c),(d) persisting La Niña summers using NCEP-NCAR R1 data. (top) The anomalous diabatic heating at $400 \mathrm{hPa}$ with a $0.2 \times 10^{-5} \mathrm{~K} \mathrm{~s}^{-1}$ interval. Stippling denotes the $90 \%$ confidence using a two-tailed Student's $t$ test. Purple boxes indicate the subtropical WP and tropical CP regions used to force the SWM in Fig. 9. (bottom) The vertical profiles of anomalous diabatic heating over the subtropical WP (dashed) and tropical CP (solid). Black lines indicate the climatological diabatic heating over these two regions.

convergence is only significant over the tropical $\mathrm{CP}$ where the suppressed convection triggered by the developing La Niña SST anomalies is located (Fig. 6e).

The RWS associated with vorticity advection by the anomalous divergent flow (Fig. 6, upper panels) is rather similar between the transitioning and persisting summers. Therefore, the primary difference in RWS between the two cases stems from the stretching effect due to the suppressed convection in the subtropical WP caused by the decaying El Niño (Fig. 6g). In the next section, we use the stationary wave model to further examine the role of the suppressed convection in the subtropical WP in strengthening the extratropical teleconnections in the transitioning summer.

\section{b. SWM results}

\section{1) Global anomalous diabatic heating}

We first force the SWM with the observed anomalous diabatic heating globally from both the transitioning and persisting summers to examine ENSO summer tropical forcing of extratropical teleconnections. The composites of anomalous diabatic heating at $400 \mathrm{hPa}$ (Fig. 7), where the strongest mean diabatic heating happens, are largely similar to the anomalous rainfall patterns (Figs. 3c,f) in the tropics. During the transitioning summer, two areas of significant anomalous cooling at $400 \mathrm{hPa}$ are observed over the tropical CP and subtropical WP, representing the two areas of suppressed convection (Fig. 7a). The vertical profiles of the anomalous diabatic heating also show the anomalous cooling throughout the troposphere over both the tropical CP and subtropical WP (Fig. 7b, orange lines), indicating the suppression of these two deep convection areas. In contrast, during the persisting summer, anomalous cooling is only observed in the tropical $\mathrm{CP}$ and not in the subtropical WP (Figs. 7c,d).

Figures $8 \mathrm{~b}$ and $8 \mathrm{e}$ show the model anomalous streamfunction in response to the global anomalous diabatic heating forcing (Fig. 7) during the two developing La 
(a) $J J A(0)_{T}$ : NCEP-NCAR RI

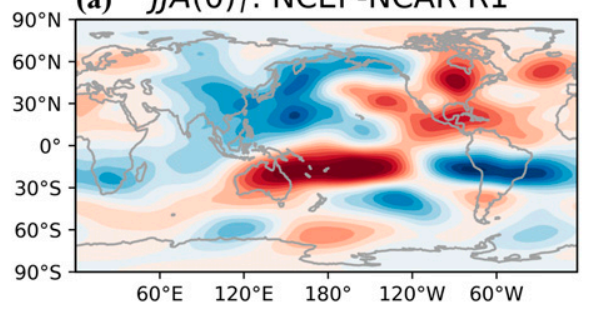

(b)
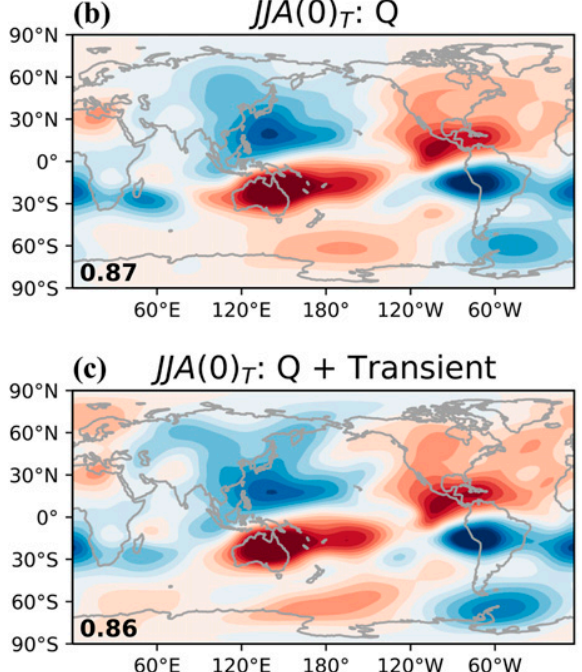

(d) JJA(0) $)_{p}$ NCEP-NCAR R1
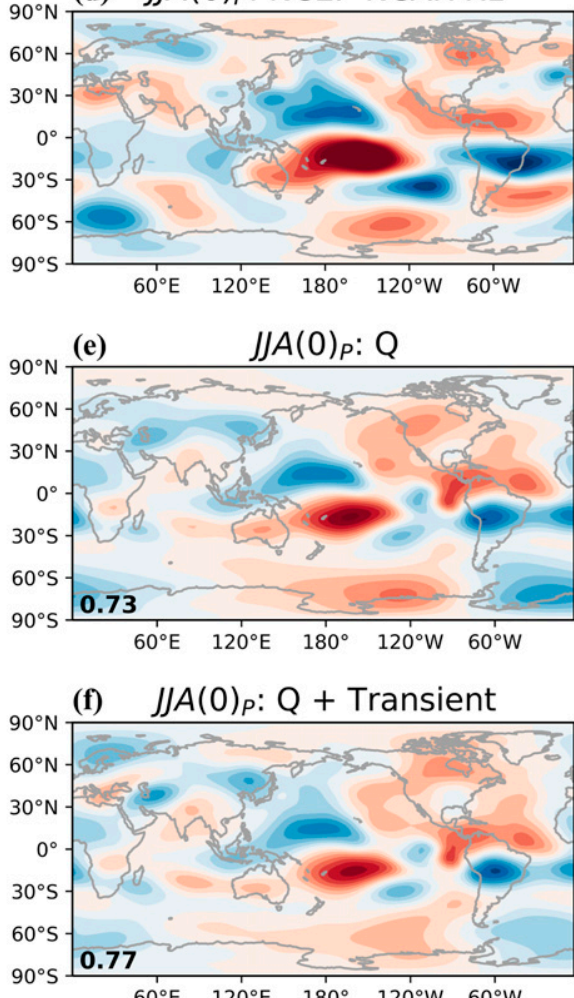

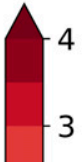

2

1

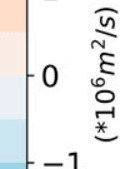

$-2$

$-3$

FIG. 8. The 250-hPa streamfunction anomalies from (a),(d) observed composites using NCEP-NCAR R1, (b),(e) the SWM forced with observed diabatic heating anomalies, and (c),(f) the SWM forced with observed diabatic heating and transient vorticity flux anomalies in the (left) transitioning and (right) persisting La Niña summers (interval: $10^{6} \mathrm{~m}^{2} \mathrm{~s}^{-1}$ ). Numbers in (b), (c), (e), and (f) indicate the pattern correlations with the observations in (a) and (d) for the PNA $\left(0^{\circ}-75^{\circ} \mathrm{N}, 120^{\circ} \mathrm{E}-60^{\circ} \mathrm{W}\right)$ region.

Niña summers. During the transitioning summer, there is a quadruple pattern of anomalous streamfunction in the tropics that resembles the Gill-Matsuno response to a tropical heat source centered off the equator (Ting and Yu 1998) and similar to the observations (Fig. 8a). The quadruple pattern is centered at around $120^{\circ} \mathrm{W}$ and extends westward to reach East Asia and Australia in both the model and the observations. The pattern correlations for the anomalous streamfunction between the observations and the model response are 0.84 for the global area and 0.87 for the PNA area $\left(0^{\circ}-\right.$ $75^{\circ} \mathrm{N}, 120^{\circ} \mathrm{E}-60^{\circ} \mathrm{W}$; Table 1 , first row). This suggests that tropical diabatic forcing is able to cause anomalous circulations outside of the tropics including North America, even though the basic-state westerlies are weak in the boreal summer. In the persisting summer (Fig. 8e), the quadruple pattern of anomalous streamfunction is weaker in amplitude and shifted farther to the east compared to the transitioning summer, though it is also similar to the observations (Fig. 8d). Unlike in the transitioning summer, the western part of the quadruple pattern only extends to around $150^{\circ} \mathrm{E}$, not reaching East Asia and Australia. The pattern correlations between the observations and the model response are 0.67 for the global area and 0.73 for the PNA area (Table 1, first row).

Tropical diabatic heating is the dominant driver of the ENSO teleconnection pattern, but the teleconnections are also influenced by midlatitude transient eddy vorticity and sensible heat fluxes (e.g., Hoerling and Ting 1994). Figures 8c and 8f show the streamfunction responses to the combination of diabatic heating and transient heat and vorticity flux convergences during the two types of La Niña summers. The primary effect of midlatitude transient eddies is to shape the details of the teleconnection patterns in the extratropics. For example, the anomalous anticyclone over the United States during the transitioning summer (Fig. 8c) becomes more distinct and like the observations in the presence of transient eddy forcing, compared to the case forced with only the diabatic heating (Fig. 8b). Similarly, the anomalous anticyclone in North America during the persisting summer 
TABLE 1. Pattern correlations for 200-hPa streamfunction anomalies from the SWM forced with observed diabatic heating anomalies and transient eddies fluxes convergence anomalies for the PNA $\left(0^{\circ}-75^{\circ} \mathrm{N}, 120^{\circ} \mathrm{E}-60^{\circ} \mathrm{W}\right.$, bold) and global (italic) regions in the transitioning and persisting La Niña summers. Pattern correlations are compared with the observed composite (Figs. 8a,d, OBS) and the outputs in response to global diabatic heating anomalies in the SWM (Figs. 8c,f) for the regional diabatic heating experiments.

\begin{tabular}{|c|c|c|c|c|}
\hline Figure No. & Forcing & Correlate with & Transition $\mathrm{JJA}_{T}(0)$ & Persistent $\mathrm{JJA}_{P}(0)$ \\
\hline Figs. $8 \mathrm{~b}, \mathrm{e}$ & Global $Q$ & OBS & $\mathbf{0 . 8 7} / 0.84$ & $\mathbf{0 . 7 3} / 0.67$ \\
\hline Figs. $8 \mathrm{c}, \mathrm{f}$ & Global $Q$ and transient eddies & OBS & $\mathbf{0 . 8 6} / 0.85$ & $\mathbf{0 . 7 7} / 0.68$ \\
\hline \multirow[t]{2}{*}{ Figs.9a,e } & $\mathrm{WP}+\widetilde{\mathrm{CP}} Q$ and transient eddies & OBS & $\mathbf{0 . 8 4} / 0.81$ & $\mathbf{0 . 8 3} / 0.69$ \\
\hline & & SWM & $\mathbf{0 . 9 6} / 0.90$ & $\mathbf{0 . 9 2} / 0.80$ \\
\hline \multirow[t]{2}{*}{ Figs. 9b,f } & CP $Q$ and transient eddies & OBS & $\mathbf{0 . 6 5} / 0.69$ & $\mathbf{0 . 8 0} / 0.64$ \\
\hline & & SWM & $\mathbf{0 . 7 9} / 0.75$ & $\mathbf{0 . 8 8} / 0.78$ \\
\hline \multirow[t]{2}{*}{ Figs. 9c,g } & WP $Q$ and transient eddies & OBS & $\mathbf{0 . 5 7} / 0.49$ & $\mathbf{0 . 0 1} / 0.07$ \\
\hline & & SWM & $0.68 / 0.61$ & $\mathbf{0 . 0 0} / 0.08$ \\
\hline
\end{tabular}

shifts northeastward and compares better with the observations (the pattern correlation in the PNA region increases from 0.73 to 0.77 ; Table 1 , second row) when the transient eddy effects are added. The strong similarity between the SWM responses and the observations suggests that the SWM forced with diabatic heating and transient eddy forcing has the ability to reproduce the observed ENSO teleconnections as well as to distinguish the difference in circulation responses between the two different developing La Niña summers.

\section{2) Regional anomalous diabatic HeAting EFFECT}

To focus on the role of diabatic cooling in the subtropical WP in the transitioning summer, we next examine the model responses to the regional diabatic heating (Fig. 9). We force the stationary wave model with the global transient vorticity forcing and regional diabatic heating over 1) both the subtropical WP and tropical CP (EXP - WP + CP; Figs. 9a,e), 2) the tropical CP (EXP - CP; Figs. 9b,f), and 3) the subtropical WP (EXP - WP; Figs. 9c,g) for both the transitioning and persisting summers.

In the transitioning summer (denoted as $\operatorname{EXP}_{T}$ ), the diabatic coolings over the subtropical WP and the tropical $\mathrm{CP}$ dominate the anomalous circulations. The anomalous circulations from $\mathrm{EXP}_{T}-\mathrm{WP}+\mathrm{CP}$ (Fig. 9a) are highly similar to the anomalous circulations forced by the global diabatic heating field (Fig. 8c) with a pattern correlation of 0.90 for the global domain and 0.96 for the PNA region (Table 1, third row). The streamfunction pattern in Fig. 9a also resembles the observations shown in Fig. 8a, with a pattern correlation of 0.81 for the global domain and 0.84 for the PNA region. When only the tropical CP diabatic cooling is prescribed to force the model (Fig. 9b), the quadruple pattern of anomalous streamfunction is much weaker in amplitude and does not extend as far to the west as when both the WP and CP diabatic cooling are included. This is also reflected in the spatial pattern correlation with the anomalous circulations forced by the global diabatic heating (Fig. 8c), which drops to 0.69 for the global domain and 0.65 for the PNA region (Table 1 , forth row). The intensity of the extratropical teleconnections is weakened, but an anomalous anticyclone is still found over North America, consistent with the classic wave train in response to the La Niña tropical forcing.

On the other hand, when only the subtropical WP diabatic cooling is applied to the model, the quadruple pattern shifts westward with the center near the date line (Fig. 9c), suggesting that the WP diabatic cooling contributes to the westward extension of the tropical response associated with the La Niña tropical CP forcing. Furthermore, the subtropical WP diabatic cooling also contributes to the anomalous anticyclone over North America with a similar amplitude as that due to the tropical CP cooling (Fig. 9b). The pattern correlations with the anomalous circulations forced by the global diabatic heating (Fig. 8c) are 0.61 for the global domain and 0.68 for the PNA region (Table 1, fifth row), comparable to the ones in $\mathrm{EXP}_{T}-\mathrm{CP}$, justifying the important role played by the subtropical WP cooling in the overall teleconnection in the transitioning La Niña summer. These results support our hypothesis that the suppressed convection over the subtropical WP can trigger stationary wave propagation toward extratropical North America and strengthen the ENSO extratropical teleconnections during the transitioning summer. The anomalous diabatic heating over the far eastern tropical Pacific and tropical Atlantic in the transitioning La Niña summer (Fig. 7a) also partially contributes to the extratropical teleconnections over North America (Fig. 9d; e.g., Kushnir et al. 2010; Wang et al. 2010), but the amplitude of the associated anomalous circulation is weaker compared to the ones forced with tropical Pacific diabatic coolings (Figs. 9a-c). 
(a)

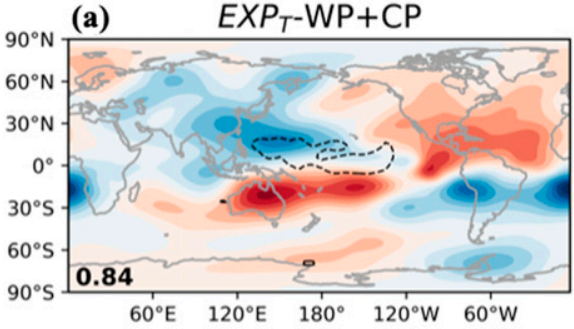

(b)

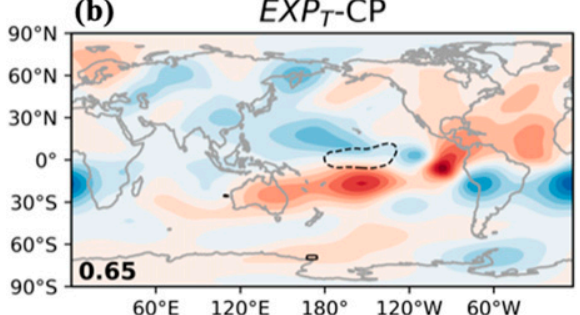

(c)

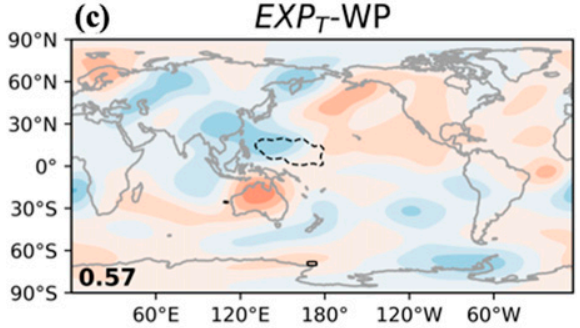

(d) $\quad E X P_{T}-E P+A t l a n t i c$

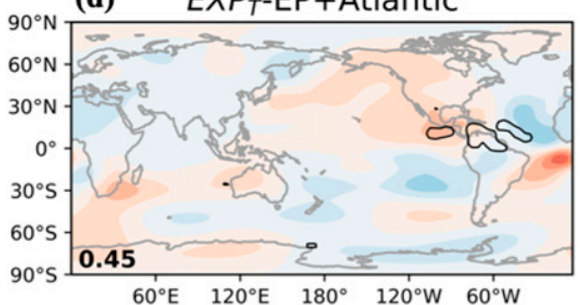

(e) $\quad E X P_{p}-\mathrm{WP}+\mathrm{CP}$
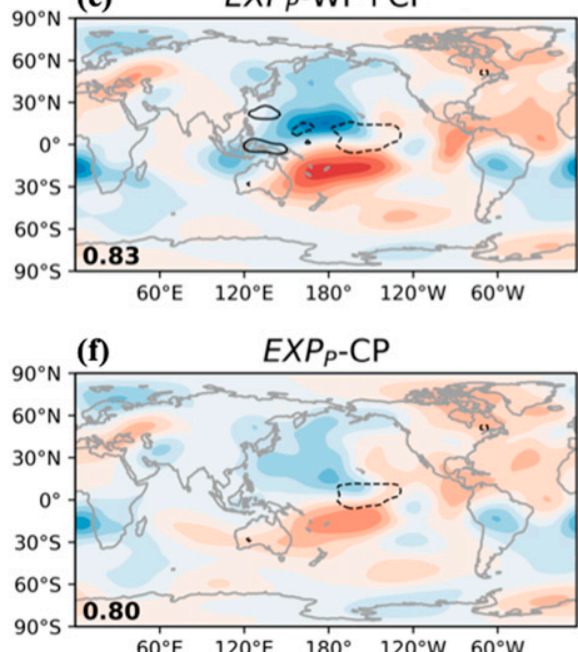

(g)

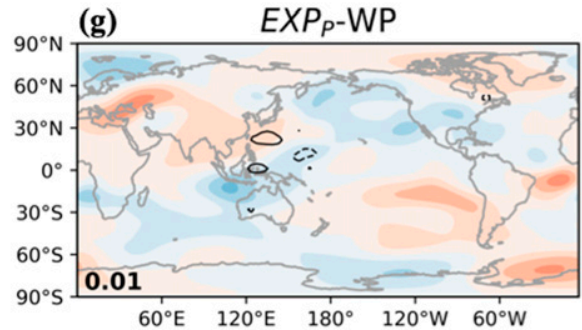

(h)

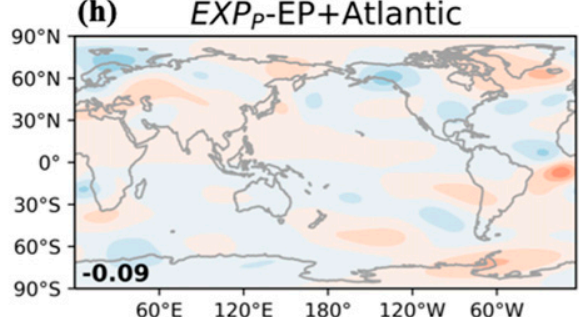

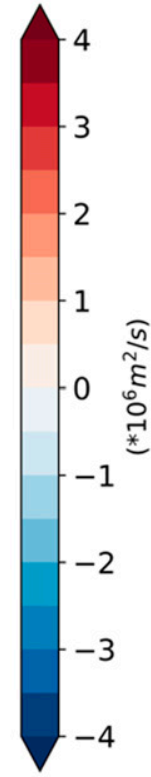

FIG. 9. The 200-hPa streamfunction anomalies from the SWM forced with regional observed diabatic heating from (a),(e) both the subtropical WP and the tropical CP, (b),(f) the tropical CP, (c),(g) the subtropical WP, and (d),(h) the far tropical eastern Pacific (EP) and Atlantic together with global transient vorticity flux anomalies in the (left) transitioning and (right) persisting La Niña summers (interval: $10^{6} \mathrm{~m}^{2} \mathrm{~s}^{-1}$ ). Dashed (solid) lines indicate the area where diabatic heating anomalies are smaller than $-0.4 \times 10^{5} \mathrm{~K} \mathrm{~s}^{-1}$ (larger than $0.4 \times 10^{5} \mathrm{~K} \mathrm{~s}^{-1}$ ). Numbers indicate the pattern correlations with the observations (Figs. 8a,d) for the PNA region. The area of regional diabatic heating anomalies are indicated in Figs. 7a and 7c.

In the persisting summer (denoted as $\operatorname{EXP}_{P}$ ), in contrast to the transitioning summer, the anomalous circulations in $\mathrm{EXP}_{P}-\mathrm{CP}$ (Fig. 9f) are similar to the ones in $\mathrm{EXP}_{P}-$ $\mathrm{WP}+\mathrm{CP}$ (Fig. 9e). The quadruple patterns in these two experiments are both similar to the anomalous circulations forced by the global diabatic heating (Fig. 8f) as well as the observations (Fig. 8d) with the center around $120^{\circ} \mathrm{W}$ and extending westward to around $150^{\circ} \mathrm{E}$. This implies that the diabatic heating over the subtropical WP is not influential in this case. Figure $9 \mathrm{~g}$ shows the anomalous circulations from $\mathrm{EXP}_{P}-\mathrm{WP}$. This shows no similarity with the observations (pattern correlation is 0.07 for the global domain and 0.01 for the PNA region; Table 1, fifth row). Hence, in the persisting summer, diabatic cooling over the tropical CP dominates the ENSO teleconnection patterns, unlike during the transitioning summer when diabatic coolings over both the tropical CP and the subtropical WP play substantial roles.

\section{Conclusions and discussion}

\section{a. Conclusions}

Here we have examined the physical mechanisms of teleconnections in developing La Niña summers when 
ENSO tropical forcing reduces soybean and maize yields in the United States. Examining the post-1950 period, a developing La Niña summer is either when an El Niño is transitioning to a La Niña (transitioning summer) or a La Niña is persisting (persisting summer). We have focused on distinguishing the dynamics of these two types of developing La Niña summers based on observations and using a stationary wave model (SWM) as a diagnostic tool.

- Transitioning and persisting summers have different SST anomaly patterns across the tropics because they have evolved differently from the preceding winters. During the transitioning summer, although the tropical Pacific has transitioned into a La Niña state, the Indian Ocean and the tropical Atlantic are still in the El Niño decaying phase. In contrast, during the persisting summer, the La Niña signal alone spans the tropics.

- Different oceanic anomalies lead to different atmospheric responses. During the transitioning summer, two suppressed deep convection areas dominate the anomalous rainfall field over the tropical Pacific: one is over the central Pacific (CP) due to the developing La Niña, and another one is over the western Pacific (WP) due to the decaying El Niño. On the other hand, during the persisting summer, only the suppressed deep convection induced by the La Niña SST forcing is present over the tropical CP.

- During the transitioning summer, the suppressed convection over the tropical CP and the subtropical WP both provide anomalous vorticity sources via the stretching effect and induce Rossby wave propagation extending to North America. These two wave trains superimpose on each other, leading to statistically significant teleconnections in the extratropics with a significant anomalous anticyclone over northeastern North America and a robust warming over the Midwest. In contrast, during the persisting summer, without the augmentation by a wave train from the subtropical WP, the teleconnection is weak and only statistically significant in the tropics with no significant temperature anomalies over the United States.

- According to the SWM experiments, the diabatic cooling over the subtropical WP and that over the tropical CP contribute roughly equally to the anomalous anticyclone over North America. During the persisting summer, the lack of forcing in the WP means diabatic cooling over the tropical CP dominates the ENSO teleconnection pattern.

Therefore, the suppressed convection over the subtropical WP in the transitioning summer distinguishes the teleconnections from those in the persisting summer. This El Niño-induced WP suppressed convection and the associated Rossby wave strengthen the extratropical teleconnection induced by the developing La Niña SST forcing, leading to a strong anomalous anticyclone and robust warm signals over the Midwest during the transitioning summer.

\section{b. Discussion}

Although the model experiments decently reproduced the observations in many aspects, the observed difference in the intensity of anomalous anticyclone between transitioning and persisting summers is much larger than in the SWM results. A plausible explanation for this discrepancy is that the intensity of the anomalous anticyclone in the observations is also affected by several other factors not included in the SWM. These possible factors include the following:

- Land-atmosphere feedback is strong in the summer, and its influence on circulation is comparable to that of remote SST forcing according to some previous studies (e.g., Koster et al. 2000; Douville 2010). Soil moisture anomalies can affect the surface meteorological conditions through changes in evapotranspiration and therefore surface heat fluxes. The resulting anomalous surface diabatic heating can modify the regional atmospheric circulation, which may further feed back to the surface meteorological conditions. This could amplify the impacts on atmospheric circulations of tropical SST (e.g., Koster et al. 2016).

- Random atmospheric internal variability could, through constructive or destructive interference, create different amplitudes of extratropical teleconnections between the transitioning and persisting La Niña summers in observations (e.g., Hoerling and Kumar 1997; Chen and Kumar 2018; Jong et al. 2018).

- The transient eddy flux anomalies are caused by changes in the midlatitude mean flow but also feed back on the midlatitude mean flow. However, this eddy-mean flow interaction is not allowed in the model as transient eddies are treated as forcing, and this could lead to errors in the amplitude of the forced response.

To summarize, the different oceanic states of different La Niña summers result in different atmospheric convection and circulation anomalies. Hence, it is necessary to separately consider the transitioning and persisting La Niña events as their teleconnections and, therefore, impacts on crop yields, are significantly different. This demonstrates that improved understanding of ENSO summer teleconnections and seasonal prediction of U.S. 
summertime hydroclimate will require further study of the seasonal evolution of ENSO characteristics within a multiyear ENSO life cycle.

Acknowledgments. This study was supported by NSF EaSM2 Grant AGS-1243204 and NOAA Award NA17OAR4310126. WBA was also funded by Columbia University Earth Institute Postdoctoral Research Program. We thank Jason Smerdon, Arun Kumar, and Andrew Robertson for feedback that improved the manuscript. We are grateful to Isla Simpson for assisting the stationary wave model. We also acknowledge three anonymous reviewers for their constructive criticisms.

\section{REFERENCES}

Alexander, M. A., I. Bladé, M. Newman, J. R. Lanzante, N.-C. Lau, and J. D. Scott, 2002: The atmospheric bridge: The influence of ENSO teleconnections on air-sea interaction over the global oceans. J. Climate, 15, 2205-2231, https://doi.org/10.1175/15200442(2002)015<2205:TABTIO>2.0.CO;2.

Anderson, W., R. Seager, W. Baethgen, and M. Cane, 2017: Life cycles of agriculturally relevant ENSO teleconnections in North and South America. Int. J. Climatol., 37, 3297-3318, https://doi.org/10.1002/joc.4916.

Chen, M., and A. Kumar, 2018: Winter 2015/16 atmospheric and precipitation anomalies over North America: El Niño response and the role of noise. Mon. Wea. Rev., 146, 909-927, https://doi.org/10.1175/MWR-D-17-0116.1.

Compo, G. P., and Coauthors, 2011: The Twentieth Century Reanalysis project. Quart. J. Roy. Meteor. Soc., 137, 1-28, https://doi.org/10.1002/qj.776.

Dee, D. P., and Coauthors, 2011: The ERA-Interim reanalysis: Configuration and performance of the data assimilation system. Quart. J. Roy. Meteor. Soc., 137, 553-597, https://doi.org/ 10.1002/qj.828.

DiNezio, P. N., and C. Deser, 2014: Nonlinear controls on the persistence of La Niña. J. Climate, 27, 7335-7355, https:// doi.org/10.1175/JCLI-D-14-00033.1.

$\longrightarrow,-$, Y. Okumura, and A. Karspeck, 2017: Predictability of 2-year La Niña events in a coupled general circulation model. Climate Dyn., 49, 4237-4261, https://doi.org/10.1007/s00382-017-3575-3.

Ding, Q., B. Wang, J. M. Wallace, and G. Branstator, 2011: Tropical-extratropical teleconnections in boreal summer: Observed interannual variability. J. Climate, 24, 1878-1896, https://doi.org/10.1175/2011JCLI3621.1.

Dommenget, D., T. Bayr, and C. Frauen, 2013: Analysis of the nonlinearity in the pattern and time evolution of El Niño Southern Oscillation. Climate Dyn., 40, 2825-2847, https://doi.org/10.1007/ s00382-012-1475-0.

Douville, H., 2010: Relative contribution of soil moisture and snow mass to seasonal climate predictability: A pilot study. Climate Dyn., 34, 797-818, https://doi.org/10.1007/s00382-008-0508-1.

— S. Bielli, C. Cassou, M. Déqué, N. M. J. Hall, S. Tyteca, and A. Voldoire, 2011: Tropical influence on boreal summer midlatitude stationary waves. Climate Dyn., 37, 1783-1798, https:// doi.org/10.1007/s00382-011-0997-1.

Fan, Y., and H. van den Dool, 2008: A global monthly land surface air temperature analysis for 1948-present. J. Geophys. Res., 113, D01103, https://doi.org/10.1029/2007JD008470.
Handler, P., 1984: Corn yields in the United States and sea surface temperature anomalies in the equatorial Pacific Ocean during the period 1868-1982. Agric. For. Meteor., 31, 25-32, https:// doi.org/10.1016/0168-1923(84)90003-0.

Harnik, N., R. Seager, N. Naik, M. Cane, and M. Ting, 2010: The role of linear wave refraction in the transient eddy-mean flow response to tropical Pacific SST anomalies. Quart. J. Roy. Meteor. Soc., 136, 2132-2146, https://doi.org/10.1002/qj.688.

Harris, I., P. D. Jones, T. J. Osborn, and D. H. Lister, 2014: Updated high-resolution grids of monthly climatic observations-The CRU TS3.10 dataset. Int. J. Climatol., 34, 623-642, https:// doi.org/10.1002/joc.3711.

Hoerling, M. P., and M. Ting, 1994: Organization of extratropical transients during El Niño. J. Climate, 7, 745-766, https://doi.org/ 10.1175/1520-0442(1994)007<0745:OOETDE > 2.0.CO;2.

—, and A. Kumar, 1997: Why do North American climate anomalies differ from one El Niño event to another? Geophys. Res. Lett., 24, 1059-1062, https://doi.org/10.1029/97GL00918.

Hoskins, B. J., and D. Karoly, 1981: The steady linear response of a spherical atmosphere to thermal and orographic forcing. J. Atmos. Sci., 38, 1179-1196, https://doi.org/10.1175/15200469(1981)038<1179:TSLROA > 2.0.CO;2.

— istic longitudinally varying flow. J. Atmos. Sci., 50, 1661-1671, https://doi.org/10.1175/1520-0469(1993)050<1661:RWPOAR> 2.0.CO;2.

$\mathrm{Hu}$, Q., and S. Feng, 2001: Variations of teleconnection of ENSO and interannual variation in summer rainfall in the central United States. J. Climate, 14, 2469-2480, https://doi.org/ 10.1175/1520-0442(2001)014<2469:VOTOEA >2.0.CO;2.

Huang, B., and Coauthors, 2017: Extended Reconstructed Sea Surface Temperature, version 5 (ERSSTv5): Upgrades, validations, and intercomparisons. J. Climate, 30, 8179-8205, https://doi.org/10.1175/JCLI-D-16-0836.1.

Iizumi, T., J.-J. Luo, A. J. Challinor, G. Sakurai, M. Yokozawa, H. Sakuma, M. E. Brown, and T. Yamagata, 2014: Impacts of El Niño Southern Oscillation on the global yields of major crops. Nat. Commun., 5, 3712, https://oi.org/10.1038/ncomms4712.

Jong, B.-T., M. Ting, and R. Seager, 2016: El Niño's impact on California precipitation: Seasonality, regionality, and El Niño intensity. Environ. Res. Lett., 11, 054021, https://doi.org/ 10.1088/1748-9326/11/5/054021.

$\longrightarrow,-$, N. Henderson, and D. E. Lee, 2018: Role of equatorial Pacific SST forecast error in the late winter California precipitation forecast for the 2015/16 El Niño. J. Climate, 31, 839-852, https://doi.org/10.1175/JCLI-D-17-0145.1.

Kalnay, E., and Coauthors, 1996: The NCEP/NCAR 40-Year Reanalysis Project. Bull. Amer. Meteor. Soc., 77, 437-471, https://doi.org/ 10.1175/1520-0477(1996)077<0437:TNYRP $>2.0$. CO;2.

Kobayashi, S., and Coauthors, 2015: The JRA-55 reanalysis: General specifications and basic characteristics. J. Meteor. Soc. Japan, 93, 5-48, https://doi.org/10.2151/jmsj.2015-001.

Koster, R. D., M. J. Suarez, and M. Heiser, 2000: Variance and predictability of precipitation at seasonal-to-interannual timescales. J. Hydrometeor., 1, 26-46, https://doi.org/10.1175/15257541(2000)001<0026:VAPOPA > 2.0.CO;2.

, Y. Chang, H. Wang, and S. D. Schubert, 2016: Impacts of local soil moisture anomalies on the atmospheric circulation and on remote surface meteorological fields during boreal summer: A comprehensive analysis over North America. J. Climate, 29, 7345-7364, https://doi.org/10.1175/JCLI-D-16-0192.1.

Kushnir, Y., R. Seager, M. Ting, N. Naik, and J. Nakamura, 2010: Mechanisms of tropical Atlantic SST influence on North 
American precipitation variability. J. Climate, 23, 5610-5628, https://doi.org/10.1175/2010JCLI3172.1.

Larkin, N. K., and D. E. Harrison, 2005: Global seasonal temperature and precipitation anomalies during El Niño autumn and winter. Geophys. Res. Lett., 32, L16705, https://doi.org/10.1029/ 2005GL022860.

Lau, K.-M., and L. Peng, 1992: Dynamics of atmospheric teleconnections during the northern summer. J. Climate, 5, 140-158, https://doi.org/ 10.1175/1520-0442(1992)005<0140:DOATDT>2.0.CO;2.

Lau, N.-C., A. Leetmaa, M. J. Nath, and H.-L. Wang, 2005: Influences of ENSO-induced Indo-western Pacific SST anomalies on extratropical atmospheric variability during the boreal summer. J. Climate, 18, 2922-2942, https://doi.org/10.1175/ JCLI3445.1.

Liang, Y.-C., J.-Y. Yu, M.-H. Lo, and C. Wang, 2015: The changing influence of El Niño on the Great Plains low-level jet. Atmos. Sci. Lett., 16, 512-517, https://doi.org/10.1002/asl.590.

Liu, A. Z., M. Ting, and H. Wang, 1998: Maintenance of circulation anomalies during the 1988 drought and 1993 floods over the United States. J. Atmos. Sci., 55, 2810-2832, https://doi.org/ 10.1175/1520-0469(1998)055<2810:MOCADT>2.0.CO;2.

Mason, S. J., and L. Goddard, 2001: Probabilistic precipitation anomalies associated with ENSO. Bull. Amer. Meteor. Soc., 82, 619-638, https:// doi.org/10.1175/1520-0477(2001)082<0619:PPAAWE > 2.3.CO;2.

McPhaden, M. J., and X. Zhang, 2009: Asymmetry in zonal phase propagation of ENSO sea surface temperature anomalies. Geophys. Res. Lett., 36, L13703, https://doi.org/10.1029/2009GL038774.

Okumura, Y. M., 2019: ENSO diversity from an atmospheric perspective. Curr. Climate Change Rep., 5, 245-257, https:// doi.org/10.1007/s40641-019-00138-7.

— , and C. Deser, 2010: Asymmetry in the duration of El Niño and La Niña. J. Climate, 23, 5826-5843, https://doi.org/10.1175/ 2010JCLI3592.1.

Rasmusson, E., and T. Carpenter, 1982: Variations in tropical sea surface temperature and surface wind fields associated with the Southern Oscillation/El Niño. Mon. Wea. Rev., 110, 354-384, https://doi.org/ 10.1175/1520-0493(1982)110<0354:VITSST > 2.0.CO;2.

Ropelewski, C. F., and M. S. Halpert, 1986: North American precipitation and temperature patterns associated with the El Niño/Southern Oscillation (ENSO). Mon. Wea. Rev., 114, 2352-2362, https://doi.org/10.1175/1520-0493(1986)114<2352: NAPATP $>2.0 . \mathrm{CO} ; 2$.

, and — 1987: Global and regional scale precipitation patterns associated with the El Niño/Southern Oscillation. Mon. Wea. Rev., 115, 1606-1626, https://doi.org/10.1175/1520-0493(1987)115<1606: GARSPP $>2.0 . \mathrm{CO} ; 2$.

Sardeshmukh, P., and B. Hoskins, 1988: The generation of global rotational flow by steady idealized tropical divergence. J. Atmos. Sci., 45, 1228-1251, https://doi.org/10.1175/1520-0469(1988)045<1228: TGOGRF $>2.0 . \mathrm{CO} ; 2$.

Seager, R., N. Naik, M. Ting, M. A. Cane, N. Harnik, and Y. Kushnir, 2010: Adjustment of the atmospheric circulation to tropical pacific SST anomalies: Variability of transient eddy propagation in the Pacific-North America sector. Quart. J. Roy. Meteor. Soc., 136, 277-296, https://doi.org/10.1002/QJ.588.
Simpson, I. R., R. Seager, M. Ting, and T. A. Shaw, 2015: Causes of change in Northern Hemisphere winter meridional winds and regional hydroclimate. Nat. Climate Change, 6, 65-70, https:// doi.org/10.1038/NCLIMATE2783.

Ting, M., and M. P. Hoerling, 1993: Dynamics of stationary wave anomalies during the 1986/87 El Niño. Climate Dyn., 9, 147164, https://doi.org/10.1007/BF00209751.

_ , and H. Wang, 1997: Summertime U.S. precipitation variability and its relation to Pacific sea surface temperature. J. Climate, 10, 18531873, https://doi.org/10.1175/1520-0442(1997)010<1853: SUSPVA $>2.0 . \mathrm{CO} ; 2$.

, and L. Yu, 1998: Steady response to tropical heating in wavy linear and nonlinear baroclinic models. J. Atmos. Sci., 55, 3565-3582, https://doi.org/10.1175/1520-0469(1998)055<3565: SRTTHI $>2.0 . \mathrm{CO} ; 2$.

Trenberth, K. E., G. W. Branstator, D. Karoly, A. Kumar, N. C. Lau, and C. F. Ropelewski, 1998: Progress during TOGA in understanding and modeling global teleconnections associated with tropical sea surface temperatures. J. Geophys. Res., 103, 14 291-14 324, https://doi.org/10.1029/97JC01444.

Wang, B., and Coauthors, 2009: Advance and prospectus of seasonal prediction: Assessment of the APCC/CliPAS 14-model ensemble retrospective seasonal prediction (1980-2004). Climate Dyn., 33, 93-117, https://doi.org/10.1007/s00382-008-0460-0.

Wang, H., S. Schubert, M. Suarez, and R. Koster, 2010: The physical mechanisms by which the leading patterns of SST variability impact U.S. precipitation. J. Climate, 23, 18151836, https://doi.org/10.1175/2009JCLI3188.1.

Wang, Z., C.-P. Chang, and B. Wang, 2007: Impacts of El Niño and La Niña on the U.S. climate during northern summer. J. Climate, 20, 2165-2177, https://doi.org/10.1175/JCLI4118.1.

Weaver, S. J., and S. Nigam, 2008: Variability of the Great Plains low-level jet: Large-scale circulation context and hydroclimate impacts. J. Climate, 21, 1532-1551, https://doi.org/10.1175/ 2007JCLI1586.1.

Webster, P. J., 1981: Mechanisms determining the atmospheric response to large-scale sea surface temperature anomalies. J. Atmos. Sci., 38, 554-571, https://doi.org/10.1175/1520-0469(1981)038<0554: MDTART $>2.0 . \mathrm{CO} ; 2$.

_ 1982: Seasonality in the local and remote atmospheric response to sea surface temperature anomalies. J. Atmos. Sci. 39, 41-52, https://doi.org/10.1175/1520-0469(1982)039<0041: SITLAR $>2.0 . \mathrm{CO} ; 2$.

, and J. Holton, 1982: Cross-equatorial response to middlelatitude forcing in a zonally varying basic state. J. Atmos. Sci., 39, 722-733, https://doi.org/10.1175/1520-0469(1982)039<0722: CERTML $>2.0 . \mathrm{CO} ; 2$.

Wu, X., Y. M. Okumura, and P. N. Dinezio, 2019: What controls the duration of El Niño and La Niña events? J. Climate, 32 , 5941-5965, https://doi.org/10.1175/JCLI-D-18-0681.1.

Xie, S.-P., K. Hu, J. Hafner, H. Tokinaga, Y. Du, G. Huang, and T. Sampe, 2009: Indian Ocean capacitor effect on Indo-western Pacific climate during the summer following El Niño. J. Climate, 22, 730-747, https://doi.org/10.1175/2008JCLI2544.1. 